\title{
Ensino de artes e literatura transposto para os itens do Enem
}

\author{
Claudia Helena Azevedo Alvarengal (D) \\ Tarso Bonilha Mazzotti" iD
}

\section{RESUMO}

$\mathrm{O}$ artigo examina seis itens de artes e literatura da prova de Linguagens, Códigos e suas Tecnologias do Exame Nacional do Ensino Médio realizado em 2015 considerando a matriz de referência que define o conjunto de habilidades e competências requeridas dos estudantes e serve para elaboração do exame. Adota-se por metodologia a análise retórica dos materiais discursivos (textuais) na perspectiva da teoria da argumentação, constituída no movimento nova retórica. A exposição dos esquemas argumentativos, sendo de caráter psicossocial, permite apreender os raciocínios que influenciam na escolha das alternativas plausíveis dos itens da prova. O resultado da análise indica os limites desse tipo de avaliação para o campo das artes e da literatura.

\section{PALAVRAS-CHAVE}

avaliação da educação básica; Exame Nacional do Ensino Médio; artes e literatura; argumentação e retórica. 


\title{
ARTS AND LITERATURE TEACHING TRANSPOSED TO ENEM QUESTIONS
}

\begin{abstract}
This article examines six exam questions of arts and literature from the Languages, Codes and their Technologies Assessments of the Exame Nacional do Ensino Médio held in 2015 against the reference matrix, which defines the required set of skills and competencies for students, and serves to the preparation of the exam's questions. We apply the methodology of rhetorical analysis of the discursive material (texts) referenced in the argumentation theory, consolidated in the new rhetoric movement. The exposure of argumentative schemes, which have a psychosocial character, allows to grasp the reasoning that influence the choices of plausible answers to the exam questions. The analysis result indicates the limits of this type of exam to the fields of arts and literature.
\end{abstract}

\section{KEYWORDS}

evaluation of basic education; Exame Nacional do Ensino Médio; arts and literature; argumentation and rhetoric.

\section{ENSEÑANZA DE ARTE Y LITERATURA TRANSPUESTA EN CUESTIONES DEL ENEM}

\section{RESUMEN}

El artículo examina seis ítems de artes y literatura de la prueba de Lenguajes, Códigos y sus Tecnologías del Exame Nacional do Ensino Médio realizado en 2015 ante la matriz de referencia, que define el conjunto de habilidades y competencias requeridos a los estudiantes, y sirve para elaboración del examen. Se adoptó la metodología de análisis retórico del material discursivo (textual) en vista de teoría de la argumentación, fundada en el movimiento de la nueva retórica. La exposición de los esquemas argumentativos, siendo de carácter psicosocial, permite comprender el razonamiento que influyen en la elección de las alternativas plausibles de las cuestiones de la prueba. El resultado del análisis indica los límites de este tipo de evaluación para el campo de las artes y la literatura.

\section{PALABRAS CLAVE}

evaluación de la educación básica; Exame Nacional do Ensino Médio; artes y literatura; argumentación y retórica. 


\section{INTRODUÇÃO}

\section{EXAME NACIONAL DO ENSINO MÉDIO - BREVE HISTÓRICO}

Este artigo tem por objetivo analisar a razoabilidade das avaliações em larga escala, por meio da exposição dos esquemas argumentativos que sustentam a sua pertinência e acuidade, tendo como corpus o Exame Nacional do Ensino Médio (ENEM), especificamente para as áreas de Artes e Literatura. No ENEM, essas áreas estão reunidas na prova de Linguagens, Códigos e suas Tecnologias cuja feitura é orientada pelo conjunto de habilidades e competências indicadas por sua matriz de referência. Considerando a teoria da argumentação como arcabouço teórico e conceitual para a análise retórica do material discursivo, este estudo pondera a respeito de seis itens (questões objetivas) da prova realizada em 2015, que são analisados em conjunto às apreciações e aos comentários de professores com formação na área de Linguagens, recolhidos em sites educacionais, blogs e vídeos. Nesse cenário de confrontação de argumentos, busca-se apreender os raciocínios que influenciam na escolha das alternativas plausíveis dos itens da prova.

$\mathrm{Na}$ conjuntura das políticas educacionais brasileiras, com a expansão do ensino, o Estado tem buscado estratégias para regular os processos de escolarização valendo-se da crença de que a escola forma o cidadão. Nessa perspectiva, na década de 1990, instituíram-se novas ações de cunho normativo com o intuito de organizar e aferir a eficiência do sistema educacional, a saber:

- a lei n. 9.394, de Diretrizes e Bases da Educação Nacional, sancionada em 1996 em substituição à lei n. 5.692/1971;

- a confecção dos Parâmetros Curriculares Nacionais (PCNs) para cada segmento da escolarização, buscando tanto orientar o ensino das diversas disciplinas com a indicação de temas transversais quanto promover o aprimoramento dos currículos;

- a criação das avaliações escolares institucionalizadas para aferir os resultados da qualidade da educação, entre os quais o Sistema de Avaliação da Educação Básica (SAEB), que serve de base para o cálculo do Índice de Desenvolvimento da Educação Básica (IDEB).

Esse conjunto de ações tem por base certo alinhamento entre desenvolvimento econômico e social, em que a avaliação qualifica a produtividade do sistema educacional (Chirinéa e Brandão, 2015).

O ENEM se enquadra nesse último item como a avaliação de final da educação básica, tendo sido instituído pela portaria n. 438, de 28 de maio de 1998, inicialmente definido como aferidor da qualidade do ensino médio com base no desempenho dos estudantes. Buscava-se apreender as competências cognitivas dos estudantes do ensino médio com vistas a projetar os rumos desse nível de escolarização. Além disso, o ENEM oferecia a oportunidade de o estudante realizar uma autoavaliação para orientar suas futuras escolhas. Então, no contexto da criação desse exame, ao final da década de 1990, o foco era avaliar competências e habilidades que integrassem os conhecimentos do cotidiano do aprendiz aos adquiridos na escola. 
Todavia, desde quando foi criado, até os dias atuais, o ENEM passou a agregar outras funções:

- selecionar os que estão aptos ao ensino superior e à participação nos programas do governo, como o Programa Universidade para Todos (ProUni) e o Sistema de Seleção Unificada (SISU);

- até 2016 certificou o término do ensino médio, sendo necessário para os estudantes que buscavam o ensino universitário, marcando tanto o término da educação básica quanto a passagem para o ensino superior;

- em 2009, quando passou por reestruturação com a publicação da portaria n. 109, de 27 de maio, os resultados do ENEM em cada área passaram a ser fornecidos também por escola, de modo que a comunidade escolar local pode comparar e avaliar a proficiência da sua escola em relação ao requerido pelo exame.

Em 2017, o ENEM deixou de certificar o ensino médio e de servir de base para medir a qualidade das escolas, permanecendo o modelo de avaliação por competências e habilidades. Para cada área do conhecimento foi projetado um conjunto de habilidades específicas referentes a competências de área definido nas matrizes de referência do exame (Brasil, 2015).

As avaliações institucionalizadas categorizam os estudantes, definem os resultados de sucesso e de fracasso escolar, projetados como índices de desenvolvimento social. Os exames escolares institucionalizados, portanto, expressam e concretizam a representação de percurso determinado e determinável (Mazzotti, 2008), uma metáfora que coordena os discursos para a educação escolar e que se sustenta no axioma fundamental das teorias pedagógicas de que é possível influenciar e modificar as crenças, atitudes e valores dos outros. A impossibilidade de garantir os meios completamente eficazes para tal processo, que caracteriza esse axioma modal da educação, ${ }^{1}$ constitui uma arena de divergências acerca das ações ditas adequadas ao ensino e aos modos de verificação do aprendizado. Sendo assim, faz-se necessário analisar de que tratam as avaliações, visto que estabelecem os preferíveis a respeito da escolarização com base em indicadores de resultado, como manifestação da aquisição de conhecimentos pelos aprendizes.

A elaboração do ENEM consolidou-se por meio de sua fundamentação nas matrizes de referência, documento que apresenta as competências de área associadas às respectivas habilidades avaliadas. A matriz de referência define cinco eixos cognitivos gerais, que atravessam as quatro áreas do conhecimento avaliadas (Linguagens, Matemática, Ciências da Natureza e Ciências Humanas):

- dominar linguagens;

- compreender fenômenos;

- enfrentar situações-problema;

1 Axioma ou ponto de partida argumentativo considerado indiscutível; modal, pois opera com modalidades no tempo (possibilidade/probabilidade). O axioma modal da educação afirma ser possível conduzir o educando do estado de não educado ao de educado. Trata-se de uma possibilidade, logo, eventualmente não se realiza. 
- construir argumentação;

- $\quad$ elaborar propostas. (Brasil, 2015, p. 66)

Para este artigo, analisamos seis itens de artes e literatura que constam na prova de Linguagens, Códigos e suas Tecnologias do referido exame realizada no ano de 2015, considerando os eixos cognitivos de sua matriz de referência. Nessa área, o ENEM aplicado em 2015 abarca conteúdos de língua portuguesa, língua estrangeira, literatura, educação física, artes e tecnologias da informação. A matriz de referência para Linguagens apresenta nove competências de área para esses conteúdos.

Confrontar as questões da prova ao que demanda a matriz permite expor como opera a transposição das competências de área para as situações-problema, também denominadas itens ou questóes objetivas. A análise do que se apresenta divergente visa também apreender o embate de perspectivas acerca do que se considera educativo para a área de Linguagens nos quesitos de arte e literatura. Os exames como tradução da matriz de referência em confluência com os conhecimentos escolares apresentam as representações acerca da escolarização, o que significa nesse contexto expor o que está naturalizado. Como os conhecimentos escolares (competências e habilidades) são representados nas questões das provas com relação às artes e à literatura? $\mathrm{O}$ que os exames revelam acerca do ensino escolar e o que significam no contexto da educabilidade nesse contexto?

A investigação acerca das perspectivas, dos valores e seus significados demanda o exame dos discursos para o qual recorremos à nova retórica, movimento que resgatou e ampliou a retórica antiga, sistematizada por Aristóteles no século V a.C. Chaïm Perelman e Lucie Olbrechts-Tyteca foram os pioneiros na reorganização desse material, resultando na publicação do Tratado da argumentação: a nova retórica, em 1958, que serve de orientação para a nossa análise.

\section{ANÁLISE RETÓRICA - TÉCNICA PARA APREENDER OS SIGNIFICADOS DOS DISCURSOS}

A nova retórica surgiu em contraponto ao tratamento lógico (formal) dado à linguagem natural e examina os meios razoáveis para se raciocinar acerca de juízos de valor, os quais não têm caráter demonstrativo. Trata-se da retomada e ampliação da retórica proposta por Aristóteles cujo projeto busca identificar os raciocínios apresentados em qualquer argumentação que se desenvolve pelas opiniões aceitas (objetos de acordo). Um argumento opera com diversos esquemas de pensamento, e a análise retórica verifica o que é preponderante à adesão e ao consentimento do auditório ao revelar hábitos, valores e verdades defendidas pelos atores sociais. Nas conversações sociais, os grupos negociam o aceitável, bem como o inadmissível, definindo, desse modo, o que é válido fazer, ter ou ser. Sendo assim, os valores sociais, postos em hierarquia, expõem os preferíveis dos grupos (Perelman e Olbrechts-Tyteca, 2005).

$\mathrm{O}$ item de uma prova apresenta um argumento que tem por base premissas admitidas, as quais constituem os objetos de ensino ao longo do processo de esco- 
larização. Tomando como base esses pontos de partida, pressupõe-se que os respondentes desenvolvam seus raciocínios para inferir as respostas aos itens. Por essa via e para este artigo, a situação social e comunicativa está colocada pelos elaboradores do exame (orador), que imprimem um éthos, e os estudantes avaliados (páthos, um auditório supostamente ambientado nesse éthos) por meio dos itens do exame (lógos, argumentos que apresentam as situações-problema com as opções de resposta).

Perelman e Olbrechts-Tyteca dispõem as técnicas argumentativas em duas grandes categorias complementares:

1. as que ligam elementos do discurso;

2. as que dissociam uma noção.

A ligação de elementos do discurso fundamenta os raciocínios por vínculos causais e de coexistência, as argumentações quase lógicas, as figuras de pensamento que originam metáforas e metonímias, entre outros esquemas do pensamento. A dissociação toma uma noção separando-as em dois termos para estabelecer uma hierarquia entre eles, na qual o segundo apresenta as qualidades verdadeiras e desejáveis (termo 2) de um lado, em contraponto às qualidades inferiores (termo 1 ), de outro.

O contexto argumentativo coloca todos os elementos que o compõe em ação: orador (éthos), discurso (lógos) e auditório (páthos) — uma tríade cuja interação estabelece o real por meio de esquemas discursivos que podem ser apresentados em diversos registros. Documentos escritos, incluindo os exames escolares, ainda que no formato de múltipla escolha, apresentam os pontos de partida admitidos pela ampla maioria dos interlocutores e servem de premissa para o desenvolvimento dos raciocínios, que resultam nas inferências (respostas) aos itens. Portanto os elementos discursivos são passíveis de análise retórica pelos argumentos que apresentam. Igualmente, a seleção do que deve ser ensinado e os modos de avaliação colocam à mostra o desejável.

A análise retórica como técnica de exposição das crenças e dos valores sociais funciona mais apropriadamente quando aparecem discursos em oposição, uma vez que a disputa se sustenta na divergência entre crenças, valores e representações de mundo por grupos sociais. No âmbito dos discursos analisados, os atores sociais são, de um lado, elaboradores da prova ou examinadores, e, de outro lado, professores com formação na área de Linguagens (literatura e artes) habituados e inseridos no contexto de treinar estudantes para esse exame em cursos preparatórios. Esses professores apresentaram suas objeções em canais de comunicação de amplo alcance, como em jornais e na Empresa Brasil de Comunicação (EBC), além de em blogs e outros meios. Nessa situação, é plausível afirmar que esses profissionais convidados a expressar seus pareceres constituem o auditório de especialistas, de oradores autorizados, diante dos elaboradores do ENEM, uma vez que têm seus argumentos reconhecidos, validados pelo amplo auditório de ouvintes/leitores, sendo grande parte constituído de estudantes interessados nessa prova - os mesmos estudantes que buscam os cursos preparatórios ministrados por esses professores com o intuito de obter melhor desempenho no exame.

Nossa escolha focaliza a exposição e a análise de itens de artes e literatura da prova de Linguagens, Códigos e suas Tecnologias do ENEM de 2015, como 
mencionado anteriormente. As opções no formato de múltipla escolha permitem desenvolver os raciocínios na direção de alternativas divergentes como resposta correta, as quais aparecem como opção de resposta no exame. Daí o interesse em compreender os limites da verificação de certas competências e habilidades por meio de um exame no formato de múltipla escolha.

\section{OS RACIOCÍNIOS QUE ORIENTAM AS ESCOLHAS PARA DEFINIR A MATRIZ DE REFERÊNCIA}

A matriz de referência do ENEM condensa as competências e habilidades naturalizadas como as relevantes a serem adquiridas pelos aprendizes. Por esse viés, esse documento tem efeito análogo ao de um axioma ao apresentar o evidente ou o aceitável, por ser de comum acordo ou ainda, em uma definição mais estrita de axioma, "as expressões sem prova consideradas válidas em seu sistema" (Perelman e Olbrechts-Tyteca, 2005, p. 15) e que servem de premissa (ponto de partida) para a elaboração dos raciocínios que os exames expõem.

A noção de "competência" admite uma pluralidade de significados por ser um termo usual. Daí a necessidade de esclarecer tal significado no âmbito da escolarização. Segundo Machado (2005), os conceitos de competência e habilidade, bem como de conhecimento, ao buscar resultado e produção, têm como referente a economia na atual conjuntura social. Assim, os termos oriundos da economia (valor, produtividade, qualidade, resultado) deslizam para a educação e ganham significados abrangentes. Igualmente, ancoram-se nas definições de Philippe Perrenoud (2000 apud Brasil, 2002c, p. 30), sociólogo, professor em ciências da educação e fundador do Laboratório de Pesquisas sobre a Inovação na Formação e na Educação (LIFE), em Genebra, nas quais competência é "a faculdade de mobilizar um conjunto de recursos cognitivos (saberes, capacidades, informações etc.) para solucionar com pertinência e eficácia uma série de situações”. As competências são relativas a "modalidades estruturais da inteligência" (Brasil, 2002a, p. 59), ou seja, constituem os esquemas que operacionalizam as habilidades, sinalizadas como "saber fazer". Não há propriamente hierarquia nem gradação entre competência e habilidade, uma vez que "por meio das ações e operações, as habilidades aperfeiçoam-se e articulam-se, possibilitando nova reorganização das competências" (Brasil, 2002a, p. 59). A metáfora da mão descreve a relação entre competência e habilidade, ao fazer a analogia entre mão e dedos, em que não é possível acionar um sem o outro (Brasil, 2002c).

A palavra "competência" também articula a ideia de "capacidade" ao mesmo tempo em que busca ampliar a noção de "saber específico". A explanação enfatiza que a definição busca conciliar aspectos em oposição:

- um caráter observável, externo, explícito dado pelo aprendizado por metas;

- outro caráter interno, implícito, que alude à organização interna do indivíduo, algo não acessível a outra pessoa, a não ser o próprio indivíduo (Brasil, 2002b). 
Nesse sentido, o próprio texto assume a condição de proximidade com o behaviorismo, não apenas no campo do "comportamento observável”, como também pela acepção de que "para ensinar é preciso traçar objetivos claros e específicos, sem ambiguidades, de tal forma que o professor possa prever que seus alunos serão capazes de alcançá-los" (Brasil, 2002b, p. 29), o que é nomeado como "pedagogia por objetivos” (Anderson e Krathwohl, 2001; Bloom, 1976) e que parece negar a contingência da atividade educativa pertinente ao axioma modal da educação. Em contraponto a essa noção, o aspecto "interno e implícito" está relacionado à funcionalidade das ações que devem ser eficazes e adequadas conforme o contexto. Para compreender as bases da concepção de "competência", colocamos a voz dos elaboradores que explicam o conceito:

[...] ela é considerada como uma capacidade geral que torna o indivíduo apto a desenvolver uma variedade de ações que respondem a diferentes situações. Competência, nesse caso, refere-se ao funcionamento cognitivo interno do sujeito. Essa concepção de competência foi formulada em contraposição à ideia de competências como comportamentos específicos, a partir das teorias de competência linguística, proposta por Chomsky (1983) e da autorregulação do desenvolvimento cognitivo, proposta por Piaget (1976). Embora divergindo a respeito da origem das competências cognitivas, esses autores têm em comum a crença de que nenhum conhecimento é possível sem haver uma organização interna. (Brasil, 2002b, p. 30)

No entanto, enquanto Chomsky sustenta o caráter inato da competência, Piaget afirma que se trata de uma qualidade adaptativa. Essa qualidade adaptativa se define pela interação do sujeito com os objetos, que é descrita por Piaget por meio das estruturas lógicas operatórias. Nessa perspectiva, o ponto alto do desenvolvimento é definido pela estrutura formal própria de um conceito, como o de número ou de massa, constituído pelas ciências (Battro, 1976; Piattelli-Palmarini, 1987).

Os elaboradores do livro publicado pelo Ministério da Educação (MEC), que apresenta os eixos conceituais e as competências para o ENEM, descrevem que outras opções de reflexão têm sido buscadas na sociologia e na antropologia. Por fim, declaram a proximidade entre as definições de competência e inteligência no campo da educação escolar:

A ressignificação da noção de competência - nos meios educacionais e acadêmicos - está muito provavelmente atrelada à necessidade de se encontrar um termo que substituísse os conceitos usados para descrever a inteligência, os quais se mostraram inadequados, quer pela abrangência, quer pela limitação. (Brasil, 2002b, p. 31)

Essa afirmativa é relevante para nosso estudo, uma vez que as propostas de avaliação de competências usuais parecem ter o mesmo implícito dos "testes de inteligência”: há algo oculto nas pessoas que pode ser revelado pelas provas ao mostrar se são mais ou menos capazes (inteligentes). Os autores sustentam que pensar a inteligência 
humana é pensar tanto a aprendizagem não apenas na situação de comportamento ou conhecimento, mas também em no que diz respeito a operações mentais como modos de adaptações em progressão. Sendo assim, a questão é se de fato é factível verificar a correspondência biunívoca entre as competências implícitas ou ocultas e os quesitos dos exames.

Com base nos cinco eixos cognitivos designados para o ENEM, supõe-se que o processo de escolarização deveria tornar possível ao estudante, primeiramente, o dominio de diferentes linguagens (matemática, artística, linguística e científica). A linguagem é o instrumento para o pensamento. $\mathrm{O}$ campo do domínio da linguagem envolve a habilidade de "ler o mundo", de ser capaz de interpretar e significar a realidade. Também abrange a capacidade de "escrever o mundo" ao transitar pela pluralidade de linguagens, entrecruzando seus significados.

O segundo eixo cognitivo tem por objetivo a compreensão de fenômenos, ou seja, construir e aplicar conceitos pertencentes a várias áreas do conhecimento (artes, história, geografia, tecnologia etc.). Esse eixo cognitivo articula as habilidades para fazer suposições, a capacidade de relacionar, interpretar, calcular, observar, entre tantas outras ações necessárias para a criação de hipóteses. Para os autores (Brasil, 2002b), o eixo vincula-se à capacidade de inferir, assim como à tomada de posição, o que se conjuga ao domínio das linguagens diversas. De acordo com as técnicas argumentativas descritas por Perelman e Olbrechts-Tyteca (2005), as ações de inferência abrangem o campo dos raciocínios baseados na estrutura do real, fundamentados na experiência cotidiana e nas crenças, expressos basicamente por ligações de sucessão (vínculos causais) e ligações de coexistência (identificação do ato como expressão de uma essência ou pessoa).

O enfrentamento de situaçôes-problema, isto é, "a capacidade de o sujeito aceitar desafios que lhe são colocados" (Brasil, 2002b, p. 34) é o terceiro eixo cognitivo. A resolução de problemas não constitui o foco desse eixo, e sim a tomada de decisões pela seleção, organização e interpretação de dados. Os argumentos de superação prevalecem:"produzir resultados com êxito", "encarar dificuldades e obstáculos","percorrendo um processo no qual ele terá que vencer obstáculos” (Brasil, 2002b, p. 34). Os argumentos de superação também estabelecem um raciocínio baseado na estrutura do real, instituindo uma progressão de valores encaminhada pelas crenças do orador. O objetivo é transcender, superar, e não propriamente atingir um objetivo (Perelman e Olbrechts-Tyteca, 2005). Nessa perspectiva, a situação-problema é comparada a um jogo que impõe limites pelas regras estabelecidas. Cabe ao indivíduo buscar a melhor solução no limite que as regras instituem.

O quarto eixo trata da construção de argumentos nos diferentes contextos, organizando o raciocínio em prol de um objetivo, seja defender uma ideia ou analisar uma afirmativa. Requer a habilidade de ponderar diferentes perspectivas a fim de viabilizar a melhor estratégia para a persuasão do interlocutor, o que evidencia os estudos retóricos como foco das habilidades requeridas.

Por fim, tem-se a elaboração de propostas considerando a diversidade sociocultural $e$ os valores humanos, em que se valoriza o estudante que atua como agente criador de projetos. Isso implica dominar os eixos cognitivos anteriormente mencionados. Esse é o instrumental cognitivo que a matriz de referência requer dos candidatos 
em todas as áreas do conhecimento e que permeia as nove competências de área avaliadas nos itens da prova de Linguagens, Códigos e suas Tecnologias do ENEM (Brasil, 2015, p. 66) a seguir:

- Competência de área 1: Aplicar as tecnologias da comunicação e da informação na escola, no trabalho e em outros contextos relevantes para sua vida.

- Competência de área 2: Conhecer e usar língua(s) estrangeira(s) moderna(s) como instrumento de acesso a informações e a outras culturas e grupos sociais.

- Competência de área 3: Compreender e usar a linguagem corporal como relevante para a própria vida, integradora social e formadora da identidade.

- Competência de área 4: Compreender a arte como saber cultural e estético gerador de significação e integrador da organização do mundo e da própria identidade.

- Competência de área 5: Analisar, interpretar e aplicar recursos expressivos das linguagens, relacionando textos com seus contextos, mediante a natureza, função, organização e estrutura das manifestações, de acordo com as condições de produção e recepção.

- Competência de área 6: Compreender e usar os sistemas simbólicos das diferentes linguagens como meios de organização cognitiva da realidade pela constituição de significados, expressão, comunicação e informação.

- Competência de área 7: Confrontar opiniões e pontos de vista sobre as diferentes linguagens e suas manifestações específicas.

- Competência de área 8: Compreender e usar a língua portuguesa como língua materna, geradora de significação e integradora da organização do mundo e da própria identidade.

- Competência de área 9: Entender os princípios, a natureza, a função e o impacto das tecnologias da comunicação e da informação na sua vida pessoal e social, no desenvolvimento do conhecimento, associando-os aos conhecimentos científicos, às linguagens que lhes dão suporte, às demais tecnologias, aos processos de produção e aos problemas que se propõem solucionar.

\section{CARACTERÍSTICAS GERAIS DO ENEM EM 2015}

Grande parte dos livros dirigidos aos estudantes que se preparam para a prova de Linguagens, Códigos e suas Tecnologias do ENEM distingue a capacidade de ler e interpretar textos como a habilidade mais exigida. Poucas são as referências encontradas para a memorização de regras. A literatura frequentemente aparece mesclada com o domínio da interpretação de texto e as artes, de modo geral, ficam subsumidas na identificação e na associação entre as várias linguagens. A música apenas aparece por meio das letras de canções como meio para testar as habilidades de língua portuguesa. Por fim, as chamadas ligadas à gramática diminuem o viés conteudista em busca de um teor que aproxima o aprendizado das regras de uso da língua ao cotidiano dos falantes. 
Assim, diferentemente das crenças de professores da língua portuguesa expostas por Bagno (1999) e Possenti (1996), entre outros autores, o aprendizado da gramática no ENEM não é posto como atributo para desenvolver as habilidades de leitura e escrita. Ao que parece, os elaboradores do exame desvinculam a compreensão e a interpretação textual da noção de que é necessário saber a norma culta (gramática normativa). Na elaboração do ENEM, o desenvolvimento cognitivo, intelectual e afetivo se dirige às capacidades de linguagem na situação comunicativa, abrangendo a compreensão da leitura e a produção de textos marcados basicamente pelo reconhecimento de diferentes gêneros textuais, o que envolve a habilidade de identificar e utilizar o registro de variante linguística adequado ao contexto comunicativo (Zirondi e Nascimento, 2006).

As questões objetivas da avaliação de Linguagens, Códigos e suas Tecnologias apresentam a mesma estrutura (esquema ou modelo):

- um texto explicativo que apresenta uma ideia ou introduz o contexto da situação-problema ou item (questão objetiva). É também chamado de texto suporte ou introdutório, ou ainda enunciado, e pode conter imagens ou outro tipo de recurso comunicativo;

- o comando da questão, também chamado de "enunciado de comando", define o que é requerido do respondente, podendo aparecer como frase para completar ou perguntar;

- cinco opções de resposta no formato de múltipla escolha, entre as quais apenas uma é a correta. É sugerido aos elaboradores do ENEM que as demais alternativas sejam plausíveis com o intuito de verificar se o aluno atende ao enunciado de comando, que define a competência e as habilidades em avaliação.

Duas ocorrências cada vez mais frequentes na elaboração do ENEM são a utilização de gêneros textuais variados e a focalização de competências contextualizadas na cultura e nas artes para testar habilidades em outros setores.

Pelas delimitações de extensão e pelo propósito deste artigo, que visa compreender o significado das artes e da literatura na educação escolar, circunscritas a questões objetivas em uma prova, nossa análise destaca seis questões (excluindo língua estrangeira, a prova tem quarenta questões) assinaladas pela divergência de respostas entre comentadores do ENEM, constituídos por professores de Linguagens, Artes e Língua Portuguesa, e o gabarito oficial.

\section{OS ITENS CONTROVERSOS PELA MULTIPLICIDADE DE RESPOSTAS PLAUSÍVEIS}

Nossa análise apresenta os itens 110,113,114,116, 118 e 123 em outra ordem. A numeração segue a prova amarela de 2015. A resposta oficial está logo abaixo das opções em múltipla escolha (Brasil, 2011).

\section{QUESTÃO 114 (Figura 1)}

O Surrealismo configurou-se como uma das vanguardas artísticas europeias do início do século XX. René Magritte, pintor belga, apresenta elementos dessa vanguarda em suas produções. Um traço do Surrealismo presente nessa pintura é o(a): 
A) justaposição de elementos díspares, observada na imagem do homem no espelho.

B) crítica ao passadismo, exposta na dupla imagem do homem olhando sempre para frente.

C) construção de perspectiva, apresentada na sobreposição de planos visuais.

D) processo de automatismo, indicado na repetição da imagem do homem.

E) procedimento de colagem, identificado no reflexo do livro no espelho.

\section{Resposta: A}

A definição do vocábulo "díspar" foi o ponto de dissensão, colocando a opção C no campo das respostas verossímeis. A professora de linguagens Maria Tereza Faria, em oposição à opção A como alternativa correta, comenta no Jornal Zero Hora (Justino, 2015) que não há elementos desiguais ou diferentes, conforme definição da palavra “díspar” nos

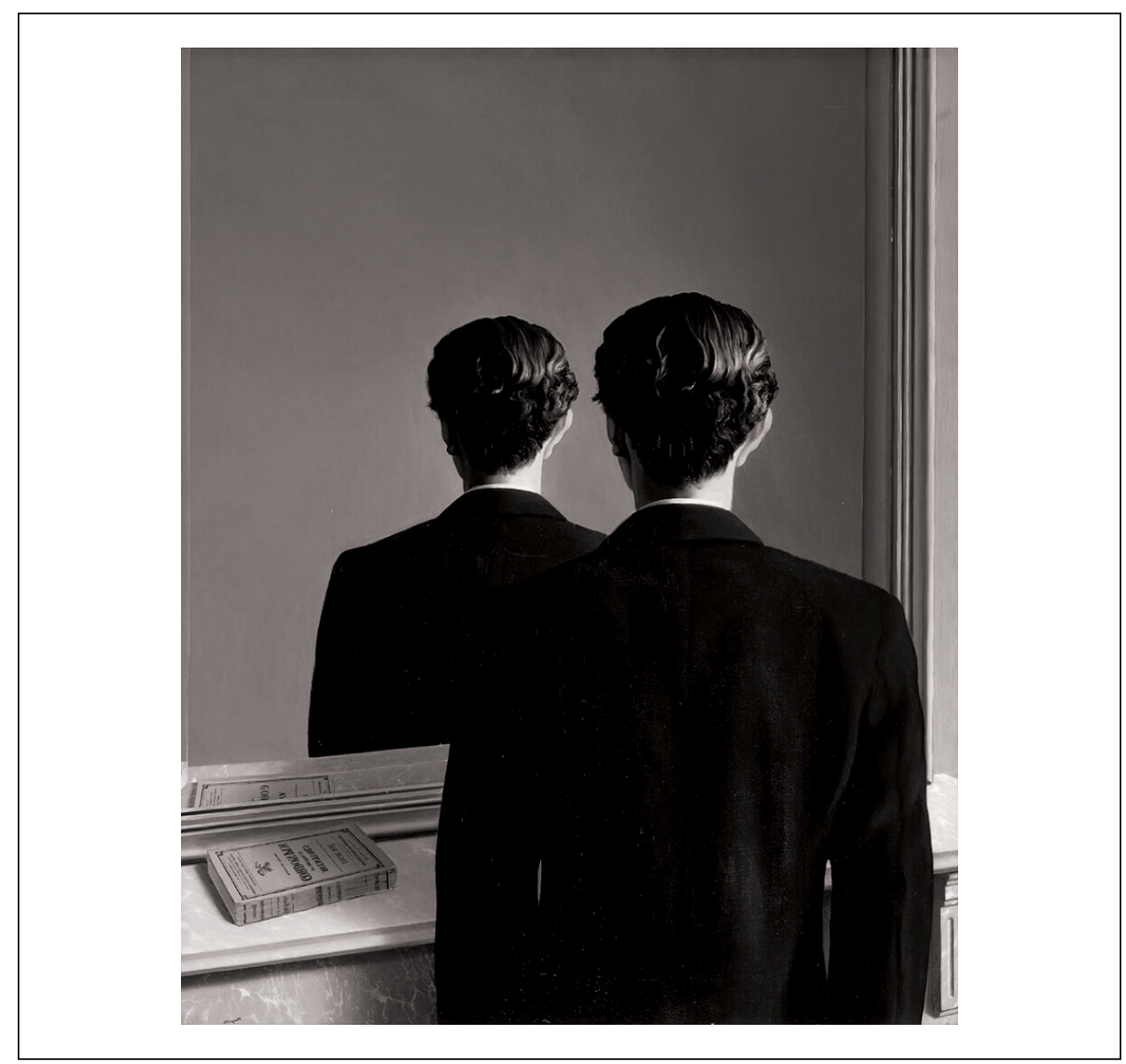

Figura 1 - René Magritte. A reprodução proibida.

Óleo sobre tela, 81,3 x 65 cm. Museum Boijmans Van Buningen, Holanda, 1937.

Fonte: ENEM (2015). 
dicionários. Segundo a professora, a simultaneidade da reflexão do livro em uma ótica convencional e das costas da figura do homem, que subverte o real, torna a alternativa $\mathrm{C}$ a mais viável, uma vez que se constitui uma nova perspectiva do olhar. Assim, conforme a comentarista, a opção A não expressa com precisão o que o enunciado requer.

\section{QUESTÃO 116 (Figura 2)}

As formas plásticas nas produções africanas conduziram artistas modernos do início do século XX, como Pablo Picasso, a algumas proposições artísticas denominadas vanguardas. A máscara remete à:
A) preservação da proporção.
B) idealização do movimento.
C) estruturação assimétrica.
D) sintetização das formas.
E) valorização estética.

\section{Resposta: D}

Nesse item, as respostas poderiam oscilar entre as opções C, D e E.

Considerando apenas o enunciado,é possível justificar a alternativa C ("estruturação assimétrica"), como característica das vanguardas em que a proposta de Pablo Picasso se insere. A mesma comentarista do item anterior (Justino, 2015) sustenta que a imagem

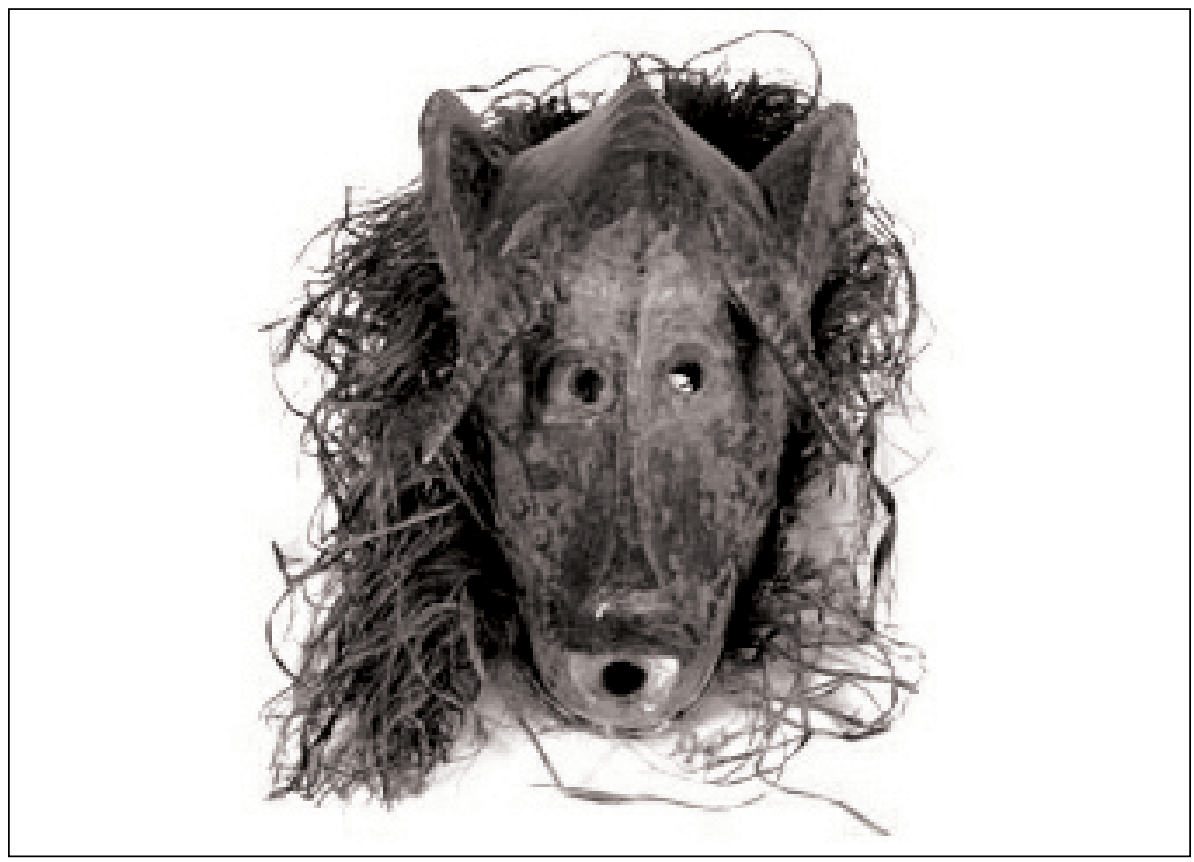

Figura 2 - Máscara senufo, Mali. Madeira e fibra vegetal. Acervo do MAE/USP.

Fonte: ENEM (2015). 
confunde o participante do ENEM. O enunciado é inconsistente para que se compreenda o que é requisitado do estudante. Tanto a assimetria do olhar na máscara, quanto os traços sintetizados são evidentes, o que justifica igualmente a escolha das opções $\mathrm{C}$ e D.

Outro argumento razoável cogitaria as opções D e E como alternativas admissíveis, visto que o primitivismo foi um movimento característico da vanguarda artística que, no início do século XX, incorporou os modos de expressão de diversos grupos étnicos, como manifestação de uma estética a ser valorizada.

Assim, o caráter imperativo da resposta em múltipla escolha que sustenta uma única resposta correta não é suficiente para afirmar a eficácia do item 116 na avaliação da competência de área 3, que trata de "compreender a arte como saber cultural e estético gerador de significação e integrador da organização do mundo e da própria identidade" (Brasil, 2015, p. 66), entrelaçado ao dominio de diferentes linguagens como eixo cognitivo. Afinal, há duas outras opções plausíveis além do gabarito oficial, e os raciocínios que definem a alternativa $\mathrm{D}$ como única e verdadeira não ficam explicitados.

A questão 118 da prova amarela apresenta uma polêmica de natureza análoga por admitir mais de uma resposta.

\section{QUESTÃO 118}

Na exposição "A Artista Está Presente”, no MoMA, em Nova Iorque, a performer Marina Abramovic fez uma retrospectiva de sua carreira. No meio desta, protagonizou uma performance marcante. Em 2010, de 14 de março a 31 de maio, seis dias por semana, num total de 736 horas, ela repetia a mesma postura. Sentada numa sala, recebia os visitantes, um a um, e trocava com cada um deles um longo olhar sem palavras. Ao redor, o público assistia a essas cenas recorrentes.

ZANIN, L. Marina Abramovic, ou a força do olhar. Disponível em: http://blogs. estadao.com.br. Acesso em: 4 nov. 2013.

O texto apresenta uma obra da artista Marina Abramovic, cuja performance se alinha a tendências contemporâneas e se caracteriza pela

A) inovação de uma proposta de arte relacional que adentra um museu.

B) abordagem educacional estabelecida na relação da artista com o público.

C) redistribuição do espaço do museu, que integra diversas linguagens artísticas.

D) negociação colaborativa de sentidos entre a artista e a pessoa com quem interage.

E) aproximação entre artista e público, o que rompe com a elitização dessa forma de arte.

Resposta: D

É factível considerar correta a opção $\mathrm{A}$ em vez da letra $\mathrm{D}$, que é a resposta oficial. $\mathrm{O}$ argumento que sustenta a letra $\mathrm{A}$ como alternativa mais adequada destaca o papel dos museus, que ultrapassa o da simples exposição de obras de arte ao proporcionar outras experiências estéticas ao público. Professores do Curso $\mathrm{Anglo}^{2}$ argumentam que "a negociação colaborativa de sentidos entre a artista e a pessoa com

2 Disponível em: <http://educacao.uol.com.br/noticias/2015/11/03/enem-2015-saibaquais-foram-as-questoes-mais-polemicas.htm>. Acesso em: 22 abr. 2017. 
quem interage" não é uma prerrogativa das tendências contemporâneas. Em entrevista ao jornal Zero Hora (Justino, 2015), a professora comentarista entende que há duas opções aceitáveis (letras A e D) e julga a escolha da letra A a mais completa por atender ao comando que ressalta o termo "tendências contemporâneas".

De fato, ao considerar que as produções artísticas representam e sumariam o caráter de uma época e de um lugar, além de concentrarem o éthos dos grupos sociais, não é possível caracterizar a "negociação colaborativa de sentidos entre a artista (éthos) e a pessoa com quem interage (páthos)" como uma tendência contemporânea. $\mathrm{O}$ inusitado e característico da contemporaneidade seria essa relação constituir o próprio objeto de produção artística, o que não fica explicitado no texto da opção $\mathrm{D}$.

Por outra perspectiva de análise, aparece mais um problema nesse item. Apesar de o texto introdutório da questão 118 utilizar o conceito de arte por tema, de fato o item é de compreensão e interpretação de texto, pois o núcleo argumentativo de apresentação deve ser compreendido pelos estudantes, sem a necessidade de recorrer a conhecimentos acerca de conceitos de arte.

Questões controversas também aparecem na área de literatura. A questão 110 foi analisada por professores no portal da EBC. Os comentadores destacaram no vídeo do quarto bloco ${ }^{3}$ que o enunciado fornece a pista para que o aluno responda corretamente. Todavia, os dois professores convidados pela EBC enunciam a letra $\mathrm{B}$ como a resposta correta, imaginam a possibilidade de os estudantes escolherem a letra A pela forma do poema remeter ao concretismo, mas não consideram a letra $\mathrm{E}$, sustentada pelo gabarito oficial. Segue o item 110:

QUESTÃO 110

\section{Casa dos Contos}

$\&$ em cada conto te cont o \& em cada enquanto me enca

nto \& em cada arco te a barco \& em cada porta $m$ e perco \& em cada lanço $t$ e alcanço \& em cada escad a me escapo \& em cada pe dra te prendo \& em cada $g$ rade me escravo \& em ca da sótão te sonho \& em cada esconso me affonso \& em cada claúdio te canto \& e $\mathrm{m}$ cada fosso me enforco \&

ÁVILA, A. Discurso da difamação do poeta. São Paulo: Summus, 1978.

3 Disponível em: <http:/www.ebc.com.br/educacao/2015/10/caiu-no-enem-professorescomentam-redacao-e-questoes-do-2o-dia-de-provas>. Acesso em: 27 abr. 2017. 
O contexto histórico e literário do período barroco-árcade fundamenta o poema Casa dos Contos, de 1975. A restauração de elementos daquele contexto por uma poética contemporânea revela que:

A) a disposição visual do poema reflete sua dimensão plástica, que prevalece sobre a observação da realidade social.

B) a reflexão do eu lírico privilegia a memória e resgata, em fragmentos, fatos e personalidades da Inconfidência Mineira.

C) a palavra "esconso" (escondido) demonstra o desencanto do poeta com a utopia e sua opção por uma linguagem erudita.

D) o eu lírico pretende revitalizar os contrastes barrocos, gerando uma continuidade de procedimentos estéticos e literários.

E) o eu lírico recria, em seu momento histórico, numa linguagem de ruptura, o ambiente de opressão vivido pelos inconfidentes.

Resposta: $\mathrm{E}$

O poema resgata a memória de dois poetas em seus contextos históricos e literários:

- a lembrança do Soneto de Gregório de Matos, poeta barroco ("A cada canto um grande conselheiro"), ao utilizar os mesmos termos no início dos versos (anáfora) para descrever a Bahia do século XVII;

- a referência nos versos finais a Cláudio Manuel da Costa, poeta árcade que esteve envolvido com os movimentos da Inconfidência Mineira e foi encontrado morto por enforcamento na prisão em uma versão oficial de suicídio. Ambos os argumentos justificam a escolha da alternativa $B$, em vez da E.

Mais uma vez, a divergência na escolha de respostas não é suficiente para examinar, no caso, a aquisição da competência de área 5, "analisar, interpretar e aplicar recursos expressivos das linguagens, relacionando textos com seus contextos, mediante a natureza, função, organização e estrutura das manifestações, de acordo com as condições de produção e recepção"(Brasil, 2015, p. 66). O respondente não tem a oportunidade de explicitar o raciocínio que o encaminha para as respostas escolhidas, o que evidencia a inadequação desse tipo de avaliação para averiguar a aquisição de certas competências no terreno da literatura, que versa acerca da ambiguidade da interpretação poética.

A situação-problema 113 é também fonte de litígios, visto que os comentadores indicam a alternativa $\mathrm{D}$ em vez da letra $\mathrm{B}$, divulgada como gabarito oficial.

QUESTÃO 113

\section{A pátria}

Ama, com fé e orgulho, a terra em que nasceste!

Criança! não verás nenhum pais como este!

Olha que céu! que mar! que rios! que floresta! 
A Natureza, aqui, perpetuamente em festa, É um seio de mãe a transbordar carinhos.

Vê que vida há no chão! vê que vida há nos ninhos,

Que se balançam no ar, entre os ramos inquietos!

Vê que luz, que calor, que multidão de insetos!

Vê que grande extensão de matas, onde impera,

Fecunda e luminosa, a eterna primavera!

Boa terra! jamais negou a quem trabalha

O pão que mata a fome, o teto que agasalha...

Quem com o seu suor a fecunda e umedece,

Vê pago o seu esforço, e é feliz, e enriquece!

Criança! não verás pais nenhum como este:

Imita na grandeza a terra em que nasceste!

BILAC, O. Poesias infantis. Rio de Janeiro: Francisco Alves, 1929.

Publicado em 1904, o poema A pátria harmoniza-se com um projeto ideológico em construção na Primeira República. O discurso poético de Olavo Bilac ecoa esse projeto, na medida em que:

A) a paisagem natural ganha contornos surreais, como o projeto brasileiro de grandeza.

B) a prosperidade individual, como a exuberância da terra, independe de políticas de governo.

C) os valores afetivos atribuídos à família devem ser aplicados também aos ícones nacionais.

D) a capacidade produtiva da terra garante ao país a riqueza que se verifica naquele momento.

E) a valorização do trabalhador passa a integrar o conceito de bem-estar social experimentado.

Resposta: B

No vídeo disponível no portal da EBC, anteriormente mencionado, a professora Zaira Dirani indica a opção $\mathrm{D}$ como resposta. Também cogita a possibilidade de o aluno marcar a letra E. Porém, a alternativa B, dada pelo gabarito oficial, não é considerada. Do mesmo modo, a professora de linguagens Maria Tereza Faria (Justino, 2015) entende que os versos 6, 9, 11,12,13 e 14 do poema de Olavo Bilac reforçam a letra D como correta.

A questão 123 também gerou um embate de respostas que afirmam a letra E como alternativa correta (Justino, 2015), em vez da opção D fornecida pelo gabarito oficial. 
QUESTÃO 123

\section{À garrafa}

Contigo adquiro a astúcia de conter e de conter-me. Teu estreito gargalo é uma lição de angústia.

Por translúcida pões

o dentro fora e o fora dentro para que a forma se cumpra e o espaço ressoe.

Até que, farta da constante prisão da forma, saltes da mão para o chão

e te estilhaces, suicida, numa explosão de diamantes.

PAES,J. P. Prosas seguidas de odes minimas. São Paulo: Cia. das Letras, 1992.

A reflexão acerca do fazer poético é um dos mais marcantes atributos da produção literária contemporânea, que, no poema de José Paulo Paes, se expressa por um(a):

A) reconhecimento, pelo eu lírico, de suas limitações no processo criativo, manifesto na expressão "Por translúcidas pões".

B) subserviência aos princípios do rigor formal e dos cuidados com a precisão metafórica, como se em "prisão da forma".

C) visão progressivamente pessimista, em face da impossibilidade da criação poética, conforme expressa o verso "e te estilhaces, suicida".

D) processo de contenção, amadurecimento e transformação da palavra, representado pelos versos "numa explosão/ de diamantes".

E) necessidade premente de libertação da prisão representada pela poesia, simbolicamente comparada à "garrafa" a ser "estilhaçada".

Resposta: D

$\mathrm{O}$ argumento que sustenta a letra $\mathrm{E}$ afirma que o "eu lírico" remete ao ato de criação poética, e não à palavra. A palavra é campo neutro, não se transforma e não contém, pois é conteúdo cuja significação condensa significante e significado. O segundo e quarto versos evidenciam que o fazer poético ("eu lírico") aprende a astúcia com a garrafa. A justificativa da comentarista apoia-se nas metáforas 
conteúdo e continente (container) de Lakoff e Johnson (1980) para fundamentar seu raciocínio. A garrafa é container (continente) enquanto a palavra é conteúdo. O estilhaçar da garrafa equivale à liberação da poesia, tornando plausível a alternativa $\mathrm{E}$ como resposta correta.

É necessário destacar que a feitura do ENEM toma por fundamento os pressupostos do interacionismo sócio-dicursivo (Zirondi e Nascimento, 2006), em um deslizamento da linguística aplicada para o campo da avaliação, matéria que abordaremos sucintamente em virtude de não constituir objeto deste artigo. $\mathrm{O}$ interacionismo sócio-discursivo investiga questões da linguagem vinculadas à atividade de interação. Mas qual é exatamente o tipo de interação tratada nesse contexto? Bronckart (2006), autor proeminente dessa abordagem, propõe um esquema de funcionamento do discurso, admitindo a influência estruturalista e reconhecendo o caráter logocêntrico, esclarecendo ainda que "as práticas de linguagem situadas (quer dizer, os textos-discursos) são os instrumentos maiores do desenvolvimento humano, não somente sob o ângulo dos conhecimentos e dos saberes, mas, sobretudo, sob o das capacidades de agir e da identidade das pessoas" (Bronckart, 2006, p. 9).

A proposta do interacionismo sócio-dicursivo é intervir nas situações práticas, especialmente no campo do ensino de línguas em que a metodologia atua especialmente sobre a produção de textos considerados standard. Texto é então definido como "uma unidade comunicativa codependente do quadro da atividade linguageira e que mobiliza os recursos de uma língua natural dada" (Bronckart, 2006, p. 22). A categoria standard opera com recursos linguísticos mais simples, servindo de base para organizar as regras que instituem modelos de texto. Nessa concepção, $a$ priori ficam excluídos dessa categoria os textos literários e artísticos, visto que estes modificam o uso das regras de base, logo, acionam recursos de linguagem de maior complexidade e com um número maior de elementos cuja interpretação opera no terreno da ambiguidade e da subjetividade.

Esse aparte pretende chamar atenção para a possível inadequação da proposta como situação-problema com alternativas fechadas (múltipla escolha) previamente dadas pela prova do exame para textos literários e artísticos, o que pode ter contribuído para o aparecimento de respostas divergentes dos professores que comentaram os itens de artes e de literatura. Ao que parece, quando o candidato tem conhecimentos mais aprofundados acerca do tema, as alternativas plausíveis parecem confundir o avaliado. Nesse sentido, é possível questionar a correspondência entre os itens de arte e literatura e as competências de área 4 e 5 , a que se deveriam vincular. A transposição da matriz de referência para o item parece difusa, incompleta e insuficiente para o propósito a que se destina, ou seja, verificar a aquisição de certas habilidades e competências.

Do mesmo modo, pela leitura dos itens apresentados no ENEM 2015, é factível sustentar que a arte se constituiu basicamente em tema para questões de compreensão textual, e não conteúdo para problematizar conhecimentos provenientes das linguagens artísticas, como define a competência de área 4: "compreender a arte como saber cultural e estético gerador de significação e integrador da organização do mundo e da própria identidade" (Brasil, 2015, p. 66). 
Nossa análise sustenta que os conhecimentos exigidos acerca da arte para a realização do ENEM são simplificados e se reduzem a clichês, tal qual as "fórmulas rituais" resultantes do "acordo sobre o modo de expressar um fato, um valor, uma ligação de fenômenos ou um relacionamento entre pessoas" (Perelman e Olbrechts-Tyteca, 2005, p. 187). O conhecimento técnico não é requerido nesse exame, quando muito é no caráter identitário que se assenta o valor das artes. A literatura também se situa nesse registro.

Nesse sentido, algumas reflexões emergem no contexto dessa análise:

- O questionamento das respostas oficiais pelos professores das áreas de Linguagens coloca à mostra um litígio conceitual e as prováveis concepções que a prova não pôde solucionar.

- Simultaneamente evidencia certa incompatibilidade entre "realizar uma prova com excelência" e "conhecer acerca de um tema", de modo que essas ações parecem não ter necessariamente vinculação. As ações cognitivas previstas nos eixos cognitivos da matriz de referência, as que permitem comparar para associar, refutar, abstrair, supor e analisar, entre outras, não ficam contempladas, ou "observáveis" para usar uma palavra que atenda às bases da psicologia e da educação, na concepção de prova cujas respostas são previamente fornecidas por múltipla escolha. Assim, a aquisição de mais conhecimentos em certas áreas não implicaria um resultado notável no ENEM. Ao contrário, ter mais conhecimentos poderia deixar o candidato em dúvida com relação às demais alternativas razoáveis ou admissíveis, uma vez que é possível conjecturar outras hipóteses de resposta, como ocorreu com os professores comentaristas das áreas de Linguagens.

- Então, da perspectiva do aprendizado de conceitos e da construção cognitiva que o ENEM pretende avaliar, o que significa inferir tomando como base enunciados de comando, como é recomendado na realização do ENEM, em confronto à concepção de aquisição de competências e habilidades, entendido como desenvolvimento cognitivo e afetivo?

\section{CONSIDERAÇÕES FINAIS ACERCA DOS SIGNIFICADOS POSTOS PELO ESQUEMA DA PROVA}

Os itens do ENEM apresentam um padrão recorrente, antes aqui já mencionado. Após o texto introdutório, há um comando que pretende dirigir o aluno para a resposta. Por sua vez, o texto introdutório apresenta o tema, pretende contextualizar o item e opera como conteúdo discursivo (texto e/ou imagem) sobre o qual o elaborador indica o comando da questão para o respondente concluir. $\mathrm{O}$ comando costuma ter duas partes. A primeira recapitula fragmentos do texto ou sugere um comentário que destaca algum ponto do texto/imagem introdutório. A seguir, determina a tarefa (ação) do aprendiz com relação ao texto/imagem para definir a melhor alternativa como resposta para a questão. 
Em um sentido amplo, é factível afirmar que o item do ENEM simula a estrutura de um silogismo, raciocínio que apresenta duas proposições (premissas maior e menor) que necessariamente conduzem a uma conclusão. Nesse caso, o texto introdutório teria a função de uma premissa maior estendida que fica sumarizada na primeira parte do comando, de modo que muitas vezes sua leitura substitui a proposta introdutória. A segunda parte do comando, que é o enunciado, opera a premissa menor. No todo, o comando sintetiza as duas proposições, em que a conclusão (resposta ao item) decorre necessariamente das ligações entre as proposições apresentadas no comando. Nesse sentido, as questões aqui selecionadas pretendem evidenciar que a prova, ao fornecer dicas para a inferência do aluno no enunciado de comando, exige dos estudantes apenas os raciocínios que já estão explicitados e são previsíveis.

O ENEM integra o universo da avaliação escolar e pressupõe que os estudantes dominem essa modalidade de avaliação como atividade. Todavia, esse exame tem características particulares que o diferenciam das avaliações que os aprendizes realizam frequentemente nas diversas disciplinas ao longo da vida escolar. Por isso a necessidade de compreender a estrutura textual que dispõe questões objetivas na forma de situações-problemas cujo propósito é didático.

$\mathrm{Na}$ perspectiva do interacionismo sócio-discursivo, Zirondi e Nascimento (2006) descrevem a avaliação do ENEM como um gênero textual específico, categorizado pelas autoras como não standard por sua complexidade, embora sustentem que essa prova opera com regras de uso comum, isto é, com regras de textos standard. Nesse ponto, concordamos parcialmente com as autoras, que entendem a estrutura textual do ENEM como complexa pela conjugação de vários textos, articulando um texto de apresentação a um comando que destaca alguma informação daquele contexto para requisitar uma operação cognitiva cuja resposta se encerra em uma das cinco alternativas fornecidas preliminarmente.

Uma determinada estrutura de texto é considerada não standard pela complexidade de operações de linguagem utilizadas e pela transformação das regras de uso comum (Bronckart, 2006), o que não ocorre nos enunciados do ENEM. Na prova de Linguagens, Códigos e suas Tecnologias, aparecem gêneros textuais standard (texto informativo, relatório, notícia, biografia etc.) e não standard (literários e artísticos), mas todos os comandos são de caráter standard, de maneira que um poema (não standard) pode aparecer como contexto para aferir o "agir" de um aprendiz por meio do comando explícito (standard) com alternativas de respostas previamente estabelecidas (também standard). Por incluir textos literários, compreendemos ser possível afirmar que o ENEM tem caráter não standard. Porém, em nossa análise, isso não é suficiente. A prova pretende avaliar a eficácia e a eficiência do ensino ao medir a aprendizagem dos alunos por meio de condutas ou do "agir" sobre a linguagem (responder às questões). Por essa via, que é objetiva, o ENEM deve constituir-se, então, em um texto standard. Sendo assim, da perspectiva conceitual que toma os pressupostos do interacionismo sócio-discursivo como base para a feitura do exame, questionamos se seria compatível vincular diretamente textos não standard (literários) e standard (por exemplo, enunciados de comando) para aferir a ação dos alunos. Tal atitude não constituiria um deslocamento do campo de ação (distor- 
ção) a que se propõe o interacionismo sócio-discursivo como teoria da linguagem acerca da produção textual, em sua origem voltada às atividades de linguagem com textos standard, para uma "didática" do ensino da língua? Aliás, foram justamente as questões tematizando literatura e artes (textos não standard) que apresentaram divergências na escolha de respostas pelos comentaristas do ENEM.

Considerando que toda avaliação escolar tem por meta verificar a aprendizagem dos estudantes, outros aspectos devem ser observados:

- O ENEM pretende averiguar em que medida os aprendizes dominam linguagens, compreendem fenômenos, enfrentam situações-problema, constroem argumentações e elaboram propostas.

- As questões objetivas (itens da prova) têm por influência as definições de situação-problema propostas por Perrenoud (Primi et al., 2001).

- A situação-problema simula um contexto desafiante que visa mobilizar os recursos cognitivos e afetivos dos estudantes para ativar esquemas com vistas à tomada de decisões convenientes à realização da tarefa, ao engendrar os raciocínios para a produção da melhor solução.

Segundo Schneuwly (2004 apud Zirondi e Nascimento, 2006), nesse modelo de avaliação, o avaliado deve comparar, analisar, interpretar e realizar inúmeras operações com a linguagem para inferir a resposta correta. Essa é uma das funcionalidades da noção de situação-problema, que no âmbito do ENEM fica restrito a um enunciado com cinco alternativas fechadas de múltipla escolha, e somente uma opção atende ao que demanda o comando.

Como foi possível verificar na seleção dos itens apresentados, os textos da prova comentada costumam fornecer informações de conteúdo e de conhecimentos necessários para que o aluno resolva a questão, entendendo que o objetivo é avaliar a capacidade de o participante do exame mobilizar o conhecimento, e não o conteúdo em si, diante de uma proposta desafiadora (Primi et al., 2001). Na mobilização do conhecimento (capacidades) emergem as ações ou condutas possíveis. Porém as respostas da prova não são abertas, pois são fornecidas preliminarmente como múltipla escolha. Afora a prova de redação, na qual os alunos têm de desenvolver seus argumentos à luz de um tema, não é factível "observar" o processo cognitivo ou o percurso dos raciocínios que os candidatos fazem para realizar suas inferências, salvo pelo resultado que é a marcação direta de uma opção. Onde estão os argumentos construídos pelos avaliados? Quais propostas elaboraram? Então seria a resposta escolhida pelo estudante suficiente para "controlar" em que medida o aprendiz acionou as habilidades para a resolução do item? Pelo exposto, não se pode afirmar que os estudantes realizem todas as operações cognitivas desejadas para esse tipo de avaliação, aqui mencionadas anteriormente, uma vez que não se oferece a oportunidade de o aluno avaliado explicitar o pensamento, como ocorre na prova de redação, em que há produção textual. Esse é um aspecto contingente que tal modelo de avaliação precisa considerar.

Os enunciados dos textos (lógos) no ENEM propõem o percurso dos raciocínios - este posto pelo enunciador, que é na realidade o elaborador do exame. De fato, o elaborador do exame (orador) institui os raciocínios que considera passíveis de serem 
avaliáveis, logo, ele sim realiza as devidas operações cognitivas (compara, analisa, interpreta) com o intuito de criar (simular/imitar) uma situação-problema para avaliar o aprendiz. Ao elaborar o enunciado do item, o orador tem metas anteriormente delineadas para apreender o desenvolvimento cognitivo dos estudantes, mas a força dessa intenção parece transferir-se para o texto. $\mathrm{O}$ interlocutor (candidato) presumido pelo orador, na situação de avaliação em múltipla escolha, deve ser capaz apenas de operar a compreensão textual pelo retorno em respostas diretas.

Diante disso, é factível afirmar que os enunciados de comando, tal qual se apresentam no ENEM, instauram um caráter que pretende subjugar a relação éthos-páthos (avaliador-avaliado) ao lógos como estrutura que condiciona o discurso, o que se torna materializado pelas categorizações de tipos de discursos e gêneros de texto, sustentadas pelo interacionismo sócio-discursivo, embora os elaboradores do ENEM sejam os enunciadores do comando da questão. De fato, isso não é uma prerrogativa do ENEM, pois as avaliações no formato de questões objetivas, sem dar oportunidade para o avaliado desenvolver argumentos, tendem a entrar nessa aporia. Cabe ao auditório, compreendido pelo universo de estudantes, ser capaz de ler ou interpretar o que é proposto pelo lógos, que nessa concepção tem muito pouco de interativo e social. Esse ajuste do aprendiz à estrutura do lógos requer o aprendizado desses esquemas, e é necessário para obter um bom resultado no exame. A distorção encontra-se na concepção de que, para os examinadores, a adaptação do páthos ao lógos, em que aquele opera a leitura ou a interpretação do proposto, significa articular as competências:

a competência para o agir do aluno pode ser caracterizada, portanto, como "saber dizer", como comunicar, explicar, compreender, racionalizar, organizar, justificar, embasar para que algo possa realizar-se enquanto expressão do pensamento, representação, compreensão ou sentido. (Zirondi e Nascimento, 2006, p. 301)

As operações cognitivas em jogo são diretivas, de sorte que o candidato só pode conjecturar ou construir hipóteses no limite do que manifestam os indicadores da prova que os elaboradores determinam. Nenhuma prova por essa via permite refutar, argumentar, criar outra solução ou mesmo questionar a resposta fornecida por seus elaboradores, como ocorreu, por exemplo, com os comentadores do ENEM, que divergiram das respostas oficiais.

$\mathrm{Na}$ conjuntura da análise do ENEM, o Instituto Nacional de Estudos e Pesquisas Educacionais "Anísio Teixeira" (INEP) entende a avaliação por situação - problema como o meio adequado para atingir os objetivos da educação escolar, em que o comando opera o "estímulo" que conduz o aluno a cumprir as tarefas. Considerando essa descrição e análise, no contexto do lógos como estrutura para fazer "agir", a avaliação do ENEM está bem mais próxima de um estatuto de formulação em via de mão única, tal como os enunciados de caráter ideológico nos sistemas de comunicação. A relação orador-auditório (éthos-páthos) é reificada pelo texto, o qual é posto no alto da hierarquia da comunicação; ao estudante cabe mover-se no contorno do repertório de "habilidades" que o comando ("estímulo") aciona. Na perspectiva da psicologia social, essa é a concepção cognitivista, na qual 
pensar significa resumidamente resolver problemas (situações-problema) e conhecer é edificar um conjunto de esquemas (comandos) de caráter lógico acerca do mundo - esquemas estes que o ENEM buscou combater nos antigos vestibulares ao condenar estruturas de memorização de regras e de conteúdos para a realização das provas. Todavia, aqui parecem retornar os mesmos delineamentos por meio de ações diretivas e monológicas sobre a linguagem, nomeadas de habilidades e competências.

\section{REFERÊNCIAS}

Anderson, L. W.; Krathwohl, D. R.(Eds). A taxonomy for learning, teaching and assessing: a revision of Bloom's taxonomy of educational objectives. New York: Longman, 2001.

Bagno, M. Preconceito linguístico o que é, como se faz. São Paulo: Edições Loyola, 1999. Battro, A. M. O pensamento de Jean Piaget. São Paulo: Forense Universitária, 1976.

B Loom, B. et al. Taxonomia de objetivos educacionais. I - Domínio cognitivo. 5. ed. Porto Alegre: Editora Globo, 1976.

Brasil. Lei n. 5.692, de 11 de agosto de 1971. Dispõe sobre as Diretrizes e Bases para o ensino de $1^{\circ}$ e $2^{\circ}$ graus. Diário Oficial da União, Brasília, DF, 12 ago. 1971.

. Lei n. 9.394, de 20 de dezembro de 1996. Estabelece as Diretrizes e Bases da Educação Nacional. Diário Oficial da União, Brasília, DF, 23 dez. 1996.

. Portaria n. 438, de 28 de maio de 1998. Institui o Exame Nacional do Ensino Médio - ENEM, como procedimento de avaliação do desempenho do aluno. Diário Oficial da União, Brasília, DF, 1 jun. 1998. Seção 1, n. 102-E, p. 5.

. Portaria n. 109, de 27 de maio de 2009. Estabelece a sistemática para a realização do Exame Nacional do Ensino Médio no exercício de 2009 (ENEM/2009). Diário Oficial da União, Brasília, DF, 28 maio 2009. Seção 1, n. 100, p. 56.

. Ministério da Educação. Instituto Nacional de Estudos e Pesquisas Educacionais Anísio Teixeira. Exame Nacional de Certificação de Competências de Jovens e Adultos (ENCCEJA). Livro introdutório: Documento básico: ensino fundamental e médio. Coordenação Zuleika de Felice Murrie. Brasília, DF: MEC; INEP, 2002a. Disponível em: <http://download.inep.gov.br/educacao_basica/encceja/material_ estudo/livro_introdutorio/introdutorio_completo.pdf>. Acesso em: 21 abr. 2016.

. Ministério da Educação. Instituto Nacional de Estudos e Pesquisas Educacionais Anísio Teixeira. Lingua Portuguesa, língua estrangeira, educação artística e educação física, Linguagens, Códigos e suas Tecnologias: livro do professor: ensino fundamental e médio. Coordenação Zuleika de Felice Murrie. Brasília, DF: MEC; INEP, 2002b. Disponível em: <http://download.inep.gov.br/educacao_basica/encceja/material_estudo/livro_ professor/linguagens_completo\%20(1).pdf>. Acesso em: 28 abr. 2016.

. Ministério da Educação. Secretaria de Educação Médio e Tecnológica. $P C N+$ Ensino Médio: orientações educacionais complementares aos Parâmetros Curriculares Nacionais. Linguagens, Códigos e suas Tecnologias. Brasília, DF: MEC; SEMTEC, 2002c. Disponível em: <http://portal.mec.gov.br/seb/arquivos/pdf/linguagens02.pdf>. Acesso em: 21 abr. 2016. 
.Instituto Nacional de Estudos e Pesquisas Educacionais Anísio Teixeira - INEP. Educação básica. 2011. Disponível em: <http://portal.inep.gov.br>. Acessos em: 2016.

. Edital n. 6, de 15 de maio de 2015. Exame Nacional do Ensino Médio ENEM 2015. Diário Oficial da União, Brasília, DF, 18 maio 2015. Seção 3, n. 92, p. 59-74. Disponível em: <http://pesquisa.in.gov.br/imprensa/jsp/visualiza/index. jsp?jornal=3\&pagina=59\&data=18/05/2015> . Acesso em: 3 maio 2016.

Bronckart, J. P. Interacionismo sócio-discursivo: uma entrevista com Jean Paul Bronckart. Revista Virtual de Estudos da Linguagem - ReVEL, [S.1.: s.n.], v. 4, n. 6, p. 1-29, mar. 2006. Tradução de Cassiano Ricardo Haag e Gabriel de Ávila Othero. Disponível em: <http://www.revel.inf.br/files/b01f783d362c4965699e1e8c41986767. pdf>. Acesso em: 2 maio 2016.

Chirinéa, A. M.; Brandão, C. F. O IDEB como política de regulação do Estado e legitimação da qualidade: em busca de significados. Ensaio: Avaliação e Políticas Públicas em Educação, Rio de Janeiro: CESGRANRIO, v. 23, n. 87, p. 461-484, jun. 2015. http:// dx.doi.org/10.1590/S0104-40362015000100019

Justino, G. Entenda as diferenças nos gabaritos oficial e extraoficial do ENEM 2015. Zero Hora, Porto Alegre, 28 out. 2015, 20h15min/Atualizada em 29 out. 2015, 11h46min. ZH Educação. Disponível em: <https://gauchazh.clicrbs.com.br/educacaoe-emprego/noticia/2015/10/entenda-as-diferencas-nos-gabaritos-oficial-e-extraoficialdo-enem-2015-4888977.html>. Acesso em: 27 nov. 2017.

Lakoff, G.; Johnson, M. Metaphors we live by. Chicago and London: The University of Chicago Press, 1980.

Machado, N. J. Interdisciplinaridade e contextuação. In: Instituto Nacional de Estudos e Pesquisas Educacionais Anísio Teixeira. Exame Nacional do Ensino Médio (ENEM): fundamentação teórico-metodológica. Brasília, DF: INEP, 2005. p. 41-53.

Mazzotti, T. B. Doutrinas pedagógicas: máquinas produtoras de litígios. Marília: Poiesis, 2008.

Possenti, S. Por que (não) ensinar gramática na escola. Campinas: Mercado de Letras; Associação de Leitura do Brasil, 1996.

Perelman, C.; Olbrechts-Tyteca, L. Tratado da argumentação: a nova retórica. Tradução de Maria Ermantina de Almeida Prado Galvão. 2. ed. São Paulo: Martins Fontes, 2005.

Perrenoud, P. L'art de construire des compétences. Nova Escola, 135, set. 2000.

Piattelli-Palmarini, M. (Org.). Teorias da linguagem, teorias da aprendizagem: o debate entre Jean Piaget e Noam Chomsky. Centre Royaumont pour une science de l'homme. Tradução de Rui Pacheco. Lisboa: Edições 70, 1987. Tradução de Théories du langage, théories de l'apprentissage: le débat entre Jean Piaget et Noam Chomsky. Paris. Editions Seuil, 1982.

Primi, R. et al. Competências e habilidades cognitivas: diferentes definições dos mesmos construtos. Psicologia: Teoria e Pesquisa, Brasília: Unb, v. 17, n. 2, p. 151-159, maio/ago. 2001. http://dx.doi.org/10.1590/S0102-37722001000200007 
Schneuwly, B. Gêneros e tipos de discurso: considerações psicológicas e ontogenéticas. In: . Gêneros textuais na escola. Tradução e organização de Roxane Rojo e Glaís Sales Cordeiro. Campinas: Mercado de Letras, 2004.

Zirondi, M. I.; Nascimento, E. L. Os enunciados de comando da prova do ENEM e sua relação com competências e capacidades para a resolução de situações-problema. Signum: Estudos da Linguagem, Londrina: UEL, v. 9, n. 2, p. 289-315, 2006.

\section{SOBRE OS AUTORES}

Claudia Helena Azevedo Alvarenga é doutora em educação pela Universidade Estácio de Sá (UNESA). Professora do Colégio de Aplicação da Universidade Federal do Rio de Janeiro (UFRJ).

E-mail: alvarengacha@gmail.com

Tarso Bonilha Mazzotti é doutor em educação pela Universidade de São Paulo (USP). Professor da Universidade Estácio de Sá (UNESA).

E-mail:tmazzotti@mac.com

Recebido em 28 de dezembro de 2017 Aprovado em 15 de junho de 2018 